\title{
Incidence and Quantitation of Pregnancy-Associated Globulin in the Japanese
}

\author{
Kaoru Sagisaka and Kenkichi Takahashi* \\ Department of Legal Medicine, Gifu University School of \\ Medicine, Gifu; and ${ }^{*}$ Department of Forensic Medicine, \\ Akita University School of Medicine, Akita
}

\begin{abstract}
Sagtsaka, K. and TAKaHASHI, K. Incidence and Quantitation of PregnancyAssociated Globulin in the Japanese. Tohoku J. exp. Med., 1976, 120 (4), 345-350 - It has been pointed out that a serum protein specific for pregnancy (prognancy-associated globulin, PAG) appears in females near term and is maintained during some period after delivery. The incidence and quantitation of PAG in 120 pregnant females and normal subjects, 1,469 males and 355 females, were studied by double diffusion and single radial immunodiffusion methods. All the pregnant females were proved to have PAG. The incidence of $P A G$ in normal males and in females over 16 years of age was $5.3 \%$ and $36.9 \%$, respectively. In the females, the incidence of PAG tended to increase with aging; $63 \%$ over 31 years of age and $100 \%$ over 51 years. Quantitative analyses, which were expressed as a percentage of the pooled preznant sera, showed that PAG of pregnant sera ranged from 24 to 240 and that of normal sera from 1 to 33 . - serum protein; pregnancy
\end{abstract}

Smithies (1959) and Afonso and Farnham (1962) showed that human pregnancy was associated with the development of unusual alpha-2-globulin in serum. Subsequently, the incidence and antigenicity of PAG have been studied by immunoassay which is more sensitive to PAG. Although it is not clear that the PAG's reported hitherto are essentially identical or not, many investigators agreed that all pregnant females near term have PAG. The present authors (1975) reported that $\mathrm{PAG}$ in blood stains of up to 4 weeks age could be detected by immunoelectrosyneresis. In the present paper, the incidence and quantitative analysis of PAG in pregnant females and normal subjects are described.

\section{Materials and Methods}

Anti-PAG serum. Anti-PAG serum was prepared by the method of Horne et al. (1973). Immunogen was pooled sera from pregnant females near term. Eight rabbits were immunized with a mixture of $0.5 \mathrm{ml}$ of the immunogen and the same volume of Freund's complete adjuvant. After 5 to 7 times weekly immunizations, all rabhits were bled. The crude sera were adsorbed with the male serum which did not contain $\mathrm{PAG}$, at an appropriate ratio in volume. The specificity of the sera was confirmed by Ouchterlony test.

Immunodiffusion test. For the Ouchterlony method, $4 \mathrm{ml}$ of $1 \%$ agar in saline were

Received for publication, July $12,1976$. 
poured on a glass plate of $2.5 \times 4.5 \mathrm{~cm}$ in size. Wells of $0.2 \mathrm{~cm}$ in diameter and $8 \mu \mathrm{l}$ in capacity at an interval of $0.5 \mathrm{~cm}$ were cut on the agar plate. The precipitation lines were observed $24 \mathrm{hr}$ after applying the antisera and samples. For single radial immunodiffusion (SRI), the antiserum was mixed with $2 \%$ agar in saline containing $0.1 \%$ sodium azide at $55^{\circ} \mathrm{C}$, and antiserum agar plates of the same size were prepared for the Ouchterlony test. Wells of $0.2 \mathrm{~cm}$ in diameter and $9 \mu \mathrm{l}$ in capacity were cut. The samples were applied and the plates were kept at $4^{\circ} \mathrm{C}$ for $72 \mathrm{hr}$ and the diameter of precipitation rings was measured. For quantitative analysis of PAG in pregnant females, the sera of 30 females which were obtained immediately after delivery were pooled. The sera were diluted $1: 1.2$, 1: 1.4, 1: 1.6 or 1: 1.8 with saline. A linear calibration curve was plotted from the size of precipitation rings of the diluted sera. For the test of normal subjects, the curve was obtained from the results of doubling dilutions (1:4 to 1:32) of the pooled sera.

Adsorption of anti-PAG serum. Anti-PAG serum was adsorbed with pooled sera of pregnant females. The similar adsorptions were done with the sera of normal subjects which contained PAG.

Serum sample. Serum samples of normal subjects were kindly supplied from the Red Cross Blood Center of Akita Prefecture. The blood donors were checked to be healthy and non-pregnant. Females who were delivered within the last 6 months were excluded. The samples of pregnant females obtained immediately after delivery were kindly provided from Dr. K. Aita of Tohoku University Hospital, and cord bloods from Dr. N. Igarashi of Akita Red Cross Hospital. The samples were stored at $-20^{\circ} \mathrm{C}$ until use.

\section{Results}

\section{Examination on sera of pregnant females}

All the sera of 120 pregnant females were found to have PAG. The quantity of PAG was expressed as a percentage of the pooled pregnant sera. As shown in Table 1, the quantity of these samples ranged from 24 to 240 , and averaged $102.7 \pm$ 45.2 (S.D.) There was a tendency to increase with aging. The correlation coefficient between age and quantity of PAG was $0.31 \quad(p<0.005)$.

TABLE 1. Quantity of $P A G$ in sera of pregnant females

\begin{tabular}{|c|c|c|c|c|c|c|c|c|c|c|c|c|c|}
\hline \multirow{2}{*}{$\begin{array}{l}\text { Age } \\
\text { group }\end{array}$} & \multicolumn{11}{|c|}{ Quantity of PAG $(\%)$} & \multirow{2}{*}{$\begin{array}{c}\text { Number } \\
\text { of } \\
\text { subjects }\end{array}$} & \multirow[b]{2}{*}{ Mean } \\
\hline & $\begin{array}{r}21^{-} \\
40\end{array}$ & $\begin{array}{r}41^{-} \\
60 \\
\end{array}$ & $\begin{array}{r}61^{-} \\
80 \\
\end{array}$ & $\begin{array}{l}81^{-} \\
100\end{array}$ & $\begin{array}{r}101^{-} \\
120\end{array}$ & $\begin{array}{r}121^{-} \\
110\end{array}$ & $\begin{array}{r}141^{-} \\
160\end{array}$ & $\begin{array}{r}161^{-} \\
180\end{array}$ & $\begin{array}{r}181^{-} \\
200\end{array}$ & $\begin{array}{r}201^{-} \\
220\end{array}$ & $\begin{array}{r}221- \\
240\end{array}$ & & \\
\hline-20 & & & & 1 & & & & & & & & 1 & 90 \\
\hline $21-25$ & 6 & 4 & 7 & 9 & 5 & 4 & 2 & 2 & & 1 & & 40 & 90 \\
\hline $26-30$ & 9 & 4 & 8 & 7 & 10 & 7 & 5 & 4 & 2 & 4 & 1 & 61 & 107 \\
\hline $31-35$ & 1 & & 3 & 1 & 2 & 3 & 2 & 1 & & $\overline{1}$ & 1 & 15 & 113 \\
\hline $36^{-}-41$ & & & & 1 & 1 & & & & & 1 & & 3 & 137 \\
\hline Total & & & & & & & & & & & & 120 & 102.7 \\
\hline
\end{tabular}

\section{Examination of sera of normal subjects and newborns}

The results of the tests of sera of 1,824 normal subjects comprising 1,469 males and 355 females over 16 years of age revealed that 78 males $(5.3 \%)$ and 131 females $(35.9 \%)$ had PAG. Analyses of age groups showed that the incidence of PAG increased with age in not only females but also males (Table 2 and Fig. 1). Especially, $63 \%$ of females over 31 years old and all of those over 51 years had PAG. The 
TABLE 2. Incidence of $P A G$ in normal subjects

\begin{tabular}{|c|c|c|c|c|}
\hline \multirow{2}{*}{ Age group } & \multicolumn{2}{|c|}{ Male } & \multicolumn{2}{|c|}{ Female } \\
\hline & $\begin{array}{c}\text { Number of } \\
\text { subjects }\end{array}$ & PAG positive & $\begin{array}{c}\text { Number of } \\
\text { subjects }\end{array}$ & PAG positive \\
\hline $16-20$ & 530 & $23(4.3 \%)$ & 149 & $40(26.8 \%)$ \\
\hline $21-25$ & 289 & $8(2.7)$ & 89 & $27(30.3)$ \\
\hline $26-30$ & 173 & $8(4.6)$ & 35 & $12(34.2)$ \\
\hline $31-35$ & 148 & $7(4.7)$ & 23 & $12(52.1)$ \\
\hline $36-40$ & 122 & $10(8.0)$ & 23 & $15(65.2)$ \\
\hline $41-45$ & 87 & $8(9.1)$ & 18 & $12(66.6)$ \\
\hline $46-50$ & 64 & $8(12.5)$ & 9 & $4(44.4)$ \\
\hline $50-$ & 56 & $6(10.7)$ & 9 & $9(100.0)$ \\
\hline Total & 1,469 & $78(5.3)$ & 355 & $131(36.9)$ \\
\hline
\end{tabular}

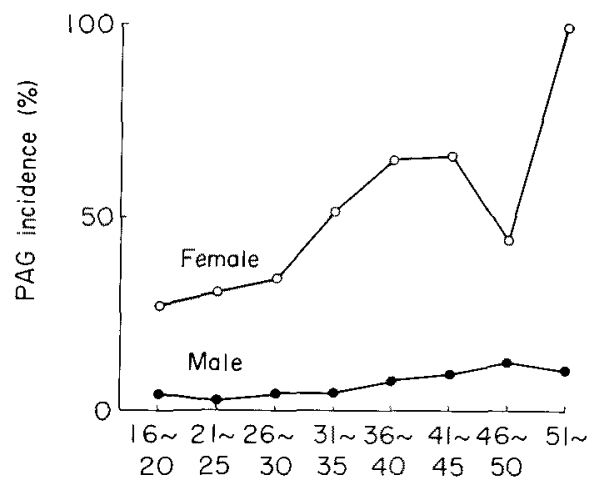

Age (years)

Fig. 1. Increase in PAG incidence of normal subjects with aging.

TABLE 3. Quantity of PAG in sera of normal males

\begin{tabular}{lccccccc}
\hline & \multicolumn{5}{c}{ Quantity of PAG (\%) } & $\begin{array}{c}\text { Number of } \\
\text { subjects }\end{array}$ & Mean \\
\cline { 2 - 7 } & -2.0 & $2.1-4.0$ & $4.1-6.0$ & $6.1-8.0$ & $8.1-10.0$ & \\
\hline $16-20$ & 7 & 9 & 5 & 2 & 23 & 3.2 \\
$21-25$ & 1 & 1 & 2 & 1 & 5 & 4.2 \\
$26-30$ & 1 & 2 & 4 & & 7 & 3.9 \\
$31-35$ & 3 & 4 & 3 & & 10 & 3.0 \\
$36-40$ & 2 & 5 & 3 & & 9 & 3.2 \\
$41-45$ & 2 & 5 & 2 & & 9 & 2.8 \\
$46-50$ & 4 & 3 & 1 & 1 & 5 & 3.8 \\
$50-$ & 1 & 2 & 1 & 1 & & 78 & 3.3 \\
\hline
\end{tabular}

incidence in females was significantly higher than in males in every age group. Quantitative analyses indicated that PAG levels of normal subjects were much lower than those of pregnant females; the mean and range were 3.3 and 1.0 to 8.0 
TABLE 4. Quantity of $P A G$ in sera of non-pregnant females

\begin{tabular}{|c|c|c|c|c|c|c|c|c|c|}
\hline \multirow[b]{2}{*}{ Age group } & \multicolumn{7}{|c|}{ Quantity of PAG (\%) } & \multirow{2}{*}{$\begin{array}{l}\text { Number of } \\
\text { subject }\end{array}$} & \multirow{2}{*}{ Mean } \\
\hline & -2.0 & $2.1-4.0$ & $4.1-6.0$ & $6.1-8.0$ & $8.1-$ & $\begin{array}{l}14.1- \\
23.0\end{array}$ & $\begin{array}{r}23.1- \\
33.0\end{array}$ & & \\
\hline $16-20$ & 16 & 9 & 10 & 3 & 2 & & & 40 & 3.4 \\
\hline $21-25$ & 9 & 5 & 6 & 5 & & 1 & & 26 & 4.2 \\
\hline $26-30$ & 1 & 1 & 6 & 3 & & 1 & & 12 & 6.2 \\
\hline $31-35$ & 3 & 1 & 1 & 3 & 2 & 2 & & 12 & 7. 7 \\
\hline $36-40$ & & 3 & 4 & 3 & 2 & 2 & 1 & 15 & 9.3 \\
\hline $41-45$ & 2 & 3 & 3 & 2 & 1 & 1 & & 12 & 5.8 \\
\hline $46-50$ & & & 2 & 2 & & & & 4 & 6.0 \\
\hline $50^{-}$ & 1 & 2 & 1 & 4 & 1 & & & 9 & 5.7 \\
\hline Total & & & & & & & & 131 & 5. 3 \\
\hline
\end{tabular}

in males, and 5.3 and 1.0 to 33.0 in females (Tables 3 and 4). The maximum value of normal females was 33 and it was slightly higher than the minimum of pregnant females. In females of ages from 16 to 40 years old the level of PAG increased slightly with age as in pregnant females. On the other hand, no such correlation was noted in the male group; the mean of PAG quantity in the teens was 3.2, whereas that in the forties 2.9. No PAG was detected in the cord blood of 100 babies.

Qualitative analysis of PAG of pregnant females and of normal subjects

In the Ouchterlony test, pregnant sera produced a distinct and one to two faint precipitation lines and sera of normal subjects usually only one, and the distinct line of pregnant sera and that of normal subjects showed a coalescent pattern (Fig. 2). When anti-PAG serum was adsorbed with pregnant sera, it had no
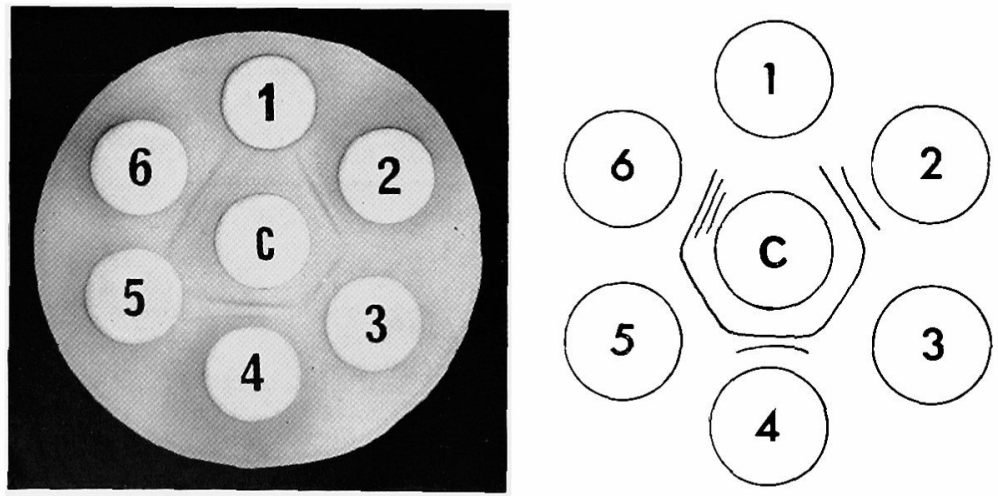

Fig. 2. Left: An Ouchterlony plate with anti-PAG serum photographed after staining with Amido black 10 B. Center well, anti-PAG serum (No. 3); peripheral well 1, serum of normal subject possessing no PAG; 2, 4 and 6 , sera of pregnant females; 3 and 5 , sera of normal subjects possessing PAG.

Right: A schema of the left plate. Sera of pregnant females produce 2-3 precipitation lines, one of which is fused with the line of normal subject. 
precipitin to PAG of normal subjects. Similarly, antiserum adsorbed with serum of normal subjects possessing PAG did not react with pregnant serum.

\section{Discussion}

The serum protein demonstrated in normal pregnancy has been studied by many investigators since the report of MacLaren et al. (1959). Afonso and Farnham (1962) reported that the pregnant zone was demonstrable in $82 \%$ of pregnant females in labor by starch gel electrophoresis. Recent works with immunoassay detected PAG in almost all sera of pregnant females. Stimson (1975) followed up PAG quantity throughout pregnancy and after delivery and revealed that the quantity reached a plateau during the third trimester and the maximum level at the delivery, then decreased rapidly. In this experiment, PAG was detected in all pregnant females, and individual variation in PAG quantity was considerable. The maximum level of PAG corresponded to ten-fold of the minimum. In our preceding paper (Sagisaka and Takahashi 1975), PAG was detectable in the blood stains kept up to 4 to 5 weeks by immunoelectrosyneresis. These test stains were prepared from pooled sera of pregnant females. Therefore, in cases of the blood stain from a pregnant female with PAG of extremely lower level, the detectable age of the stains might be shorter. It was also noteworthy that there were a few normal subjects having PAG of relatively high level.

As for the incidence, PAG positive sera were found in $18 \%$ of normal subjects (MacLaren et al. 1966), 49.4\% of females, 9.8\% of males and $8 \%$ of children (Kasukawa et al. 1973). In the present study, the incidence in normal males and females were $5.3 \%$ and $35.9 \%$, respectively, and the incidence in females increased with aging. A slight correlation between age and the quantity was observed. It has become apparent by recent work of Lin et al. (1974a, b, c) that PAG is composed of several subcomponents, and some of them have been characterized. The increasing patterns of PAG incidence and of PAG quantity with aging were not identical in the present study. This fact might suggest that the development and increase of PAG depend upon plural factors. It may be considered that PAG's of various sources should be analysed from the standpoints of the subcomponents, although few serological differences were observed between PAG of pregnant females and that of normal subjects in the Ouchterlony and adsorption tests.

As for PAG in cord blood, Afonso and Farnham (1962) denied the presence, and the similar result was obtained by the present authors. However, Toth and Zsolnai (1974) reported that PAG was found in cord blood but not in amniotic fluid. This discrepancy may suggest different composition of the antibody of anti-PAG serum used which was discussed by Lin and Halbert (1975) in detail.

\section{Acknowledgment}

We are indebted to Dr. T. Kudo, Department of Forensic Medicine, Tohoku University School of Medicine, for collecting the test materials. 


\section{References}

1) Afonso, J.F. \& Farnham, N.G. (1962) Studies on a new electrophoretic zone in labor and the puerperium and in newborn infants. Amer. J. Obstet. Gynec., 84, 199-205.

2) Horne, C.H.W., MacLay, A.L.C., Tavadia, H.B., Carmichael, I., Mallinson, A.C., Yeung Laiwah, A.A.C., Thomas, M.A. \& MaeSween, R.N.M. (1973) Studies on pregnancy-associated globulin. Clin. exp. Immunol., 13, 603-611.

3) Kasukawa, R., Yoshida, H. \& Yoshida, T. (1973) An inherited and pregnancy-associated alpha-2-globulin in Japanese sera. Int. Arch. Allergy, 44, 302-308.

4) Lin, T.M., Halbert, S.P., Kiefer, D. \& Spellacy, W.N. (1974a) Three pregnancyassociated human plasma proteins; Purification, monospecific antisera and immunological identification. Int. Arch. Allergy, 47, 35-53.

5) Lin, T.M., Halbert, S.P. \& Spellacy, W.N. (1974b) Measurement of pregnancyassociated plasma proteins during human gestation. J. Clin. Invest., 54, 576-582.

6) Lin, T.M., Halbert, S.P., Kiefer, D., Spellacy, W.N. \& Gall, S. (1974c) Characterization of four human pregnancy-associated plasma proteins. Amer. J. Obstet. Gynec., $118,223-236$.

7) Lin, T.M. \& Halbert, S.P. (1975) Immunological comparison of various human pregnancy-associated plasma proteins. Int. Arch. Allergy, 48, 101-115.

8) MacLaren, J.A., Thornes, R.D., Roby, C.C. \& Reid, D.E. (1959) An immunologic characteristic of the serum of normal pregnancy. Amer. J. Obstet. Gynec, 78, 939-946.

9) MacLaren, J.A., Reid, D.E., Konugres, A.A. \& Allen, Jr. F.H. (1966) Pal, a new inherited alpha-2-globulin of human serum. Vox Sang., 11, 553-560.

10) Sagisaka, K. \& Takahashi, K. (1975) Identification of pregnancy from blood stains by anti-pregnancy-associated globulin serum. Acta Crim. Japon, 41, 245-249.

11) Smithies, O. (1959) cited from reference 1.

12) Stimson, W.H. (1975) Variations in the serum concentration of a human pregnancyassociated alpha-macroglobulin during pregnancy and after delivery. J. Reproduct. Fert., 43, 579-582.

13) Toth, M. \& Zsolnai, B. (1974) Immunological investigation of serum proteins in pregnancy. Acta Chir. Acad. Sci. Hungaricae Tomus, 15, 273-282. 